\title{
A IMPOSIÇÃO FICCIONAL EM O AVESSO DA VIDA E OS FATOS, DE PHILIP ROTH
}

Adriano Schwartz Universidade de São Paulo

\section{RESUMO}

Este artigo busca discutir a relação entre ficção e autobiografia na obra de Philip Roth, com destaque para os livros $O$ avesso da vida, romance de 1986 que é sua experiência ficcional mais radical, e $O s$ fatos, texto "autobiográfico" que ele publica logo depois, em 1988. O propósito da análise é mostrar como os volumes estão entrelaçados, que nos dois existe de modo contínuo o choque entre vida e invenção e que esta, a invenção, invariavelmente se impõe.

PALAVRAS-CHAVE: Ficção. Romance contemporâneo. Autobiografia. Philip Roth.

\section{Philip Roth, vida e ficção ${ }^{1}$}

Poucos autores misturam tanto vida e ficção quanto Philip Roth. E não apenas no sentido que se tornou quase corriqueiro na ficção contemporânea, do uso, no romance, de fatos da vida transfigurados, mas também na direção inversa: a vida de Roth foi tão preenchida e transformada por sua ficção quanto a sua ficção por sua vida. Basta pensar em sua relação com a atriz britânica Claire Bloom, que entrou em crise depois que o escritor mostrou para ela o manuscrito de Deception (Mentiras, 1991), no qual o personagem do marido se chamava Philip e sua mulher, traída seguidas vezes no texto, Claire. É nesse romance, aliás, que o protagonista atesta a profunda confusão entre invenção e realidade em sua trajetória de 
personagem que "compartilha" a existência com seu criador: "Quando eu escrevo ficção, me dizem que é autobiografia; quando escrevo autobiografia, me dizem que é ficção. Assim, já que eu sou tão apagado e eles tão espertos, eles que decidam o que o livro vai ser ou deixar de ser" (ROTH, 1991, p. 166).

Deception é inteiramente redigido em uma espécie de modo dramático, apenas com diálogos ocorridos em momentos próximos a relações sexuais. Em uma dessas conversas, a esposa do escritor ficcional, que descobrira um caderno de anotações em que são narradas conversas muito parecidas com as que estamos lendo no livro, diz que se sentira humilhada pelo texto. O protagonista responde:

Como é que você pode se sentir humilhada por uma coisa que não existe? Não sou eu. Está longe de ser eu. É um jogo, uma brincadeira, uma fantasia a respeito de mim mesmo! Sou eu servindo de ventríloquo para mim mesmo. Ou talvez seja mais fácil de entender pelo outro lado: tudo aqui é falso, menos eu. Talvez sejam as duas coisas. Mas não importa: se for as duas coisas ou só uma delas, é tudo, querida, obra do homo ludens! (ROTH, 1991, p. 167).

Philip Roth está aqui em seu elemento favorito, o jogo de identidades transitórias que ele aprendeu a jogar no início de sua carreira e que manteve quase até o final de sua produção. A fala do personagem Philip citada acima é muito similar à do escritor Philip Roth em uma famosa entrevista concedida à Hermione Lee no mesmo período:

Criar uma biografia falsa, uma história falsa, inventar uma existência meio imaginada com base no drama real da minha vida é a minha vida. Precisa existir um prazer nesse trabalho, e é esse. Sair por aí disfarçado. Atuar como um personagem. Se passar por quem não é. Fingir. As artimanhas e astúcias da mascarada. Pense no ventríloquo (in LEE, 1992, p. 166-167).

Muitos críticos, às vezes relutantemente, consideram que, por provocar essa indistinção entre fato e ficção, Roth deve ser colocado na lista dos "autores pós-modernos". É o que afirma, por exemplo, Tuerk, para quem Roth está ali porque a ficção pós-moderna manipula o leitor para que seja impossível para ele saber se deve ou não "suspender a descrença" (TUERK em ROYAL, 2005, p. 137).

Como tentei mostrar em outro artigo (SCHWARTZ, 2013), esse jogo pode, contudo, estar vinculado a outras regras, manipulando não o 
leitor, mas as próprias condições de sua existência. Essa tendência autobiográfica que inunda o projeto ficcional de Roth se manifesta igualmente em uma série de obras recentes de autores distintos - valendo-se de diferentes estratégias narrativas -, mas, paradoxalmente, ela parece apontar com uma frequência significativa para um mesmo objetivo, a busca de validação do ficcional em um ambiente nada propício² .

Antes de discutir como isso acontece em um ou dois textos de Roth, talvez valha a pena dar mais um exemplo de como, na obra do autor, não só a vida transfigura a ficção, mas como também a ficção altera a vida, agora para introduzir a principal invenção do escritor, o personagem Nathan Zuckerman. Para tanto, será preciso lembrar o que aconteceu em 1968 e 1969, quando ele lançou Portnoy's Complaint (O complexo de Portnoy, 2013).

A jornalista Claudia Roth Pierpont, em sua biografia intelectual do autor, afirma que o livro "foi um dos atos subversivos mais salientes de uma época subversiva" e lembra que, antes mesmo de seu lançamento, o semanário Life o considerou "um dos grandes eventos na cultura americana" (PIERPONT, 2014, p. 79). Publicado em fevereiro de 1969, o romance, que reunia longas falas de um personagem controverso dirigidas ao seu psicanalista, nas quais a masturbação e sua fixação pela mãe eram temas centrais, teve trechos antecipados em revistas e transformou repentinamente o jovem Roth em uma "celebridade". Ele se mudou para Nova York, se tornou um dos autores mais conhecidos do país e enriqueceu. Nos dez anos seguintes, produziu cinco romances de alcance estético mediano e teve então a percepção que transformaria para sempre a sua obra. Resolveu tomar um personagem secundário de um desses romances, Nathan Zuckerman, que aparecera em My Life as a Man, de 1974, e transformá-lo em seu duplo ficcional. Se Roth começara a sua carreira artística chocando os rabinos de sua comunidade com os contos de Goodbye, Columbus, em 1959, Zuckerman amplificaria as ofensas em The Ghost Writer ( $O$ escritor fantasma, 2009); se ele transformara a sua vida com as transgressões de Portnoy, Zuckerman faria o mesmo com as transgressões de Carnovsky em Zuckerman Unbound (Zuckerman libertado, 2009); se Roth sofrera posteriormente a Portnoy tanto com repercussões físicas quanto com a incapacidade de criar algo tão inovador e interessante como o livro que mudara tudo, Zuckerman levaria situações semelhantes ao limite em The Anatomy Lesson (Lição de anatomia, 2009). Em sua trilogia inicial de Zuckerman, Roth toma 
a sua própria vida para examinar os sentidos e ausências de sentido de ser um artista na segunda metade do século 20, dos ritos de passagem necessários à descoberta de uma voz pessoal e peculiar à infinita angústia do esvaziamento da capacidade criativa. Sua obra transfigura sua vida, sua vida serve de modelo para a sua obra.

\section{A imposição da ficção}

A lista narrative-1@georgetown.edu é talvez o mais importante fórum de discussão sobre estudos da narrativa na internet nos últimos anos. Uma troca de mensagens ocorrida ali no início de julho de 2017 pode servir para introduzir o romance de Roth que se buscará discutir aqui. Alguém colocou no ar uma pergunta sobre textos em primeira pessoa que narram a morte do próprio narrador. Dentre as várias sugestões oferecidas não demorou a surgir The Counterlife (1987), no Brasil traduzido como $O$ avesso da vida (2008). Trata-se de uma das obras mais ambiciosas do autor, certamente a mais intrincada, e, talvez por isso, um de seus textos menos lidos, ainda que tenha sido muito elogiado por leitores bastante especiais: em uma carta de maio de 1986, por exemplo, Susan Sontag afirma que o romance se tornara a sua obra favorita de um dos maiores escritores vivos ${ }^{3}$. É um livro que também tem como protagonista Nathan Zuckerman e que ficou meio deixado de lado entre o Zuckerman inicial, presente nos "três romances e um epílogo" reunidos posteriormente no volume Zuckerman acorrentado (2011), e retomado no final da carreira de Roth em Fantasma sai de cena (2008), e o Zuckerman observador da história norte-americana, que aparece em Pastoral americana (1998), Casei com um comunista (1998) e A marca humana (2002).

Para muita gente, a estrutura circular, com suas repetições com variação, de The Counterlife pode ter sugerido que se tratava de uma diversão literária sem maiores consequências do escritor ${ }^{4}$, e nessa diversão, de fato, para retomar a sugestão publicada na lista de que o narrador em primeira pessoa morre, Nathan Zuckerman morre. Mas, como esteve na moda dizer nos últimos tempos, "só que não". Só que não, Nathan Zuckerman não morre ali, e só que não, não, não se trata de uma diversão literária sem maiores consequências. Como acontece com frequência na produção de Roth, romances publicados em períodos próximos podem ser agrupados, e o texto parceiro de The Counterlife é a "autobiografia" de Roth, The Facts (Os fatos, 2016). Da leitura em conjunto dos dois volumes, o leitor pode apreender uma espécie de exercício de mergulho 
na ficção em profundidades variadas; em um, o esforço é para, sem sair dela, ficar o mais próximo possível da superfície; no outro, ocorre o oposto, busca-se pesquisar quão fundo se pode chegar.

Na sequência deste texto, irei me ater inicialmente ao primeiro "só que não", o de que Nathan Zuckerman não morre em The Counterlife, tentando mostrar quais as suas causas para sugerir pelo menos uma implicação dessa afirmação. Para tanto, é preciso arriscar um resumo das cinco partes do texto. Na primeira, "Basel", o irmão de Nathan, Henry, resolve fazer uma cirurgia cardíaca porque os remédios que ele vinha tomando para lidar com seu problema no coração o haviam deixado impotente e morre. Na segunda, "Judea", Henry não morre na cirurgia e viaja para Israel, onde se torna um vigoroso defensor da causa judaica e onde recebe uma visita do irmão Nathan. Na terceira parte, "Aloft", Nathan Zuckerman está voltando de uma viagem a Israel e termina involuntariamente por se envolver em um mirabolante plano de sequestro do avião onde está. Na quarta parte, "Glaucestershire", é Nathan, e não Henry, que precisa passar por uma cirurgia cardíaca para evitar a impotência, e é Nathan que morre (é aqui, portanto, que Nathan teria morrido...). Na quinta parte, "Christendon", Nathan está casado com uma mulher inglesa, Maria (que fora amante de Henry, e não de Nathan, no primeiro capítulo $)^{5}$ e ambos estão esperando um filho. Para complicar as coisas, às aparentes contradições e sequências causais não lógicas da narrativa juntam-se uma profusão de trocas de pontos de vista, com narradores alternados em primeira e terceira pessoa, os encaixes de diferentes tipos de texto dentro do texto (cartas, diários, rascunhos), inúmeras passagens hipotéticas e algumas quebras do contrato ficcional, com personagens discutindo e rejeitando os papéis que vinham desempenhando na obra.

As dificuldades de lidar com o romance, que, como se viu, existem até o presente, já apareciam com os primeiros leitores. A escritora Mary McCarthy mandou uma carta para Roth no dia 11 de janeiro de 1987 para agradecer o envio de The Counterlife e para comentar o li$v{ }^{6}$. Ela afirma que gostou muito da obra até os dois capítulos finais, que pareceram a ela conter um "severo caso de antiantissemitismo". A "seção inglesa" do texto ofendeu o "cristianismo inexistente" da escritora, com a sua discussão sobre o Natal. Ela também afirma não ter entendido por que tanto fervor sobre o tema da circuncisão, se Nathan Zuckerman não é um judeu praticante. 
Roth responde alguns dias depois, em 17 de janeiro. E, de maneira muito educada e respeitosa (a leitura das cartas e dos comentários que ele faz sobre críticas e resenhas mostra que isso não é tão comum assim), comenta os diferentes pontos levantados por McCarthy. Para ele, Zuckerman nunca teria se disposto a casar com uma cristã se achasse que todos os não judeus são antissemitas, ainda que ele encontre esse tipo de retórica na sua viagem a Israel. A ironia, segundo Roth, decorre do fato de que essa discussão, que ele não julgava importante, força passagem na sua vida depois dos eventos na Inglaterra (a conversa com a irmã de Maria e as posições da mãe dela). E Roth afirma que acredita que pela primeira vez em qualquer obra de fícção se mostra como um judeu se sente quando confrontado com as questões do Natal e da encarnação.

Aí aparece o trecho mais importante da carta, Roth diz que vai falar agora como um novelista (ele diz que McCarthy se preocupou muito com questões de fora da narrativa). A hipotética circuncisão de um eventual filho aparece no texto, Roth recorda, apenas como resposta ao hipotético batismo desse eventual filho mencionado por Maria. Roth afirma: "se você não quer acreditar em mim, ouça a própria Maria", e cita um trecho de uma carta escrita por ela no romance. Mas o mais importante é o que ele não diz, ou diz que não vai dizer. Roth indica que na verdade a carta não foi escrita por Maria, e sim por Zuckerman, mas este é um assunto sobre o qual ele não quer se pronunciar.

Essa carta de Mary McCarthy ressurge entre a correspondência de Roth guardada na Biblioteca do Congresso dos Estados Unidos em uma outra carta, escrita por Cynthia Ozick e respondida dessa vez com bastante irritação por Roth. A carta de Ozick não está lá, ou seja, temos acesso somente à resposta de Roth, de dezembro de 1988, e não fíca claro como ela veio a tomar conhecimento dos termos da carta de McCarthy. Por ela, inferimos que Ozick discordou da resposta de Roth, já que ele teria se preocupado mais com as questões literárias da discussão do que com um suposto antissemitismo presente nas críticas. E aí Roth não tem grandes pudores. Desqualifica os comentários de Ozick e desqualifica os comentários de McCarthy de um modo como não havia feito diretamente, terminando com um parágrafo revelador, que reproduzo na íntegra:

"Você se prende ao estético: estrutura literária, contexto literário." Se por essa acusação você quer dizer que eu lembro ao leitor (mesmo que seja um leitor que não é nenhum ingênuo das coisas estéticas) para deixar de lado as suas indignações e retornar para uma segunda olha- 
da nas palavras que de fato estão na página - prestar atenção a quem está dizendo o que para quem, ao que está exatamente sendo dito, ao por que aquilo está sendo dito naquelas circunstâncias, qual a relação que aquela circunstância tem com os eventos prévios e com os que virão depois, qual o impacto daquela circunstância não nas memórias queridas ou sentidas ou nas convicções dogmáticas do leitor, mas no romance - é isso que fiz, e com todo respeito a você, de quem eu prezo tanto a afinidade literária e o entendimento amigo, eu ainda prefiro a carta que escrevi à carta que você sugere que eu deveria ter escrito. ${ }^{7}$

A teoria literária constatou há décadas que a opinião de um autor sobre seu próprio texto é apenas isso, uma opinião entre tantas outras. Mas não é bem isso o que acontece aqui. $\mathrm{O}$ apelo de Roth é para que o texto seja lido, para que os leitores "deem uma segunda olhada nas palavras", o que não parece ter acontecido na época em que o livro foi lançado nem agora, no quase presente da mensagem na lista de discussão. Salvo engano, quem primeiro "leu" as palavras direito foi a crítica italiana Pia Masiero, em um artigo publicado recentemente (2014), com isso contrariando inclusive o mais importante estudo sobre o conjunto das aparições de Zuckerman na obra de Roth, escrito por ela mesma três anos antes disso, Philip Roth and The Zuckerman Books: The Making of a Storyworld (2011).

Para entender o que ela viu, é preciso retomar o primeiro capítulo do romance. Quando começa a obra, temos por cerca de dez páginas o relato da doença de Henry, de seu caso com a secretária Wendy e de seu sofrimento pelo fato de a medicação necessária para contornar a doença ter como efeito colateral a sua impotência, que tornava o caso impossível. O texto está em itálico. O itálico desaparece, então, e encontramos a seguinte declaração: "Desnecessário dizer que estas não eram as três mil palavras com que Carol tinha contado quando lhe telefonou na noite anterior ao enterro para, apesar de tudo que levara os irmãos a se separar, pedir a Zuckerman se ele podia escrever um discurso fúnebre" (ROTH, 2008, p. 16).

Ou seja, instado a escrever algumas palavras para ler no funeral do irmão, Zuckerman escrevera sobre infidelidade e impotência. Tal discurso evidentemente não é lido e, no restante do capítulo, acompanhamos os procedimentos do velório, do enterro e da reunião de amigos e família que veio depois, alternados com trechos das anotações que Zuckerman fizera sobre outro caso que o irmão tivera anos antes, com Maria. Mais do que 
isso, contudo, acompanhamos no personagem escritor a ânsia incontrolável de transformar a vida em ficção. Primeiro ele pensa:

Ótimo, ótimo. Mas e aí, e as três mil palavras? O problema era que palavras moralmente impróprias para um funeral eram exatamente as palavras que o cativavam. Não fazia 24 horas que Henry morrera quando a narrativa começou a queimar no bolso de Zuckerman [...]. Essa profissão (de escritor) fode até com a dor (ROTH, 2008, p. 17).

A sensação vai crescendo ao longo do capítulo, em pequenas passagens que indicam que será impossível não concretizá-la. Até que, cerca de trinta páginas depois, surge o trecho crucial:

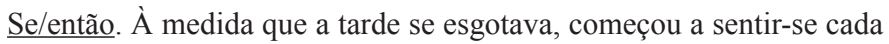
vez mais inclinado na direção de uma ideia que liberaria aquelas velhas anotações de sua crueza factual e transformaria todas num quebra-cabeça a ser resolvido pela sua imaginação. Enquanto fazia xixi no banheiro de cima, pensou: "Suponha que naquela tarde em que ela veio escondida até essa casa [...]. Não, não são eles, pensou Zuckerman, e desceu para a sala de estar [...]. Mas aí, também não precisa ser eles poderia ser eu. Nós. E, se em vez do irmão cuja existência contraditória a minha deduziu, fosse eu o Zuckerman naquela agonia? Qual é o verdadeiro critério da situação? Poderia ser simples para alguém? Se de fato aqueles remédios incapacitam a maioria dos homens que precisam deles para viver, então existe uma bizarra epidemia de impotência neste país cujas implicações pessoais ninguém está investigando (ROTH, 2008 , p. 47 , grifos meus).

Como nota MASIERO (2014, p. 7), esse trecho não ocupa um lugar especial no capítulo e está colocado junto a outras duas passagens magistrais, passando assim facilmente despercebido pelo leitor ${ }^{8}$. Mas o que está ali, na sequência de termos que vão surgindo: "se/então", "suponha que", "poderia ser eu. Nós"; "e se em vez dele fosse eu", "implicações que ninguém está investigando", é dessa investigação que o livro trata. A partir de um evento real no universo ficcional, a morte de Henry, The Counterlife faz um mergulho na mente de um escritor, Nathan Zuckerman, que, como seu criador, Philip Roth, está o tempo inteiro transfigurando vida em invenção. A continuidade de capítulos traz variações de "se/então", de suponha que, de se em vez dele fosse eu. Nathan Zuckerman não morre, portanto, em The Counterlife, exceto na ficção que ele mesmo imagina momentaneamente para pensar como teria sido a sua vida e o fim de sua vida se fosse ele, e não o irmão, que precisasse passar pela fatídica cirurgia cardíaca. 
Esse conhecimento do personagem escritor e de suas intenções provoca uma curiosa consequência. Ao mesmo tempo em que Zuckerman "investiga" formas de manipular o material que tem em mãos, o leitor, cúmplice dessa investigação, conhece cada vez mais o próprio investigador. E esse investigador muitas vezes dissimula, exagera nas investigações. Só que ele não é um narrador não confiável da mesma forma que é, por exemplo, Bentinho, em Dom Casmurro. Bentinho conta a sua história, e cabe ao leitor fazer inferências, preencher lacunas, modular motivações. Com Zuckerman acontece o oposto, aqui a informação é excessiva, as correspondências entre escritor ficcional ficionalizado, escritor ficcional e escritor real são reiteradamente usadas para suspeitas piscadelas ao leitor. A manipulação, aqui, é anunciada.

Em uma conversa com a irmã de Maria, Sarah, no capítulo 4, Zuckerman diz: "não sou um exibicionista suficientemente desavergonhado [...] só posso me exibir disfarçado. Toda a minha audácia provém de máscaras" (ROTH, 2008, p. 199). E pouco depois ouve: "Acho que você está levando uma vida de impostor" (p. 201).

Como se percebe, talvez seja difícil inicialmente ajustar as regras do jogo que se está jogando em The Counterlife. Uma vez expostas, contudo, o jogo fica claro. Isso não quer dizer que então ele se torne um jogo fácil de jogar.

Tomemos um exemplo retirado do segundo capítulo do romance. Zuckerman começa a se lembrar de uma conversa com Maria quando ambos tinham um caso, nos Estados Unidos, antes de se mudarem juntos para Londres. Ela diz a ele ser uma mulher muito comum e que, por conhecer seus livros, sabia de seus gostos sexualmente "avançados" e que ele era muito "consciente para se apaixonar" (ROTH, 2008, p. 75). Zuckerman não aceita os argumentos e insiste que está apaixonado. Aí, Maria pergunta por que ele se casaria com ela, teria um filho e aceitaria viver acomodado como todo mundo em uma vida hipócrita. A resposta é a seguinte: "Porque eu decidi abandonar a ficção artificial de ser eu mesmo em troca da genuína e satisfatória falsidade de ser outra pessoa. Case comigo" (p. 75).

A frase já implicaria torções interpretativas se tivesse sido dita em um contexto ficcional corriqueiro, em uma situação ordinária de uma história sendo contada por um narrador qualquer que dá a voz a seu personagem. No contexto do livro, tem-se, contudo, um personagem dizendo que resolveu abandonar a ficção artificial de ser ele mesmo em troca da 
falsidade de ser outra pessoa em uma memória inventada pelo próprio personagem em um exercício criativo incontornável de criar versões ficcionais da própria vida e da vida daqueles que são próximos, sendo este personagem, Zuckerman, por sua vez, uma espécie de retrato distorcido do autor que o concebeu. Como se percebe - e a complicação da frase anterior não é circunstancial -, há de fato muita "consciência" envolvida aqui, mas não necessariamente das possibilidades de se apaixonar de Zuckerman. O duelo de espelhos quebrados - e os resultantes reflexos enganosos - reforçado incansavelmente em The Counterlife trabalha com um propósito bastante enfático: ele quer potencializar o alcance ficcional do texto.

\section{A imposição ficcional de novo, agora meio dis- farçada}

Ao analisar The Counterlife como uma diversão literária, para voltar ao segundo "só que não" mencionado anteriormente, a crítica se aproximou da suposição de que Roth estaria cansado de ser confundido com seu personagem mais importante e que, para quebrar o vínculo, enquadrou-o em uma narrativa em que tantas coisas diferentes e não sequenciais aconteciam com ele que o viés biográfico de leitura se tornaria impensável. Como escreve Claudia Roth Pierpont, o autor comentava "que ele tinha que matar Zuckerman 'só para fazer as pessoas pararem de dizer que eu escrevo apenas sobre minhas experiências" (PIERPONT, 2014, p. 206).

Em uma perspectiva teórica mais sofisticada, mas ainda próxima dessa, The Counterlife funcionaria como um exercício que retrata a diluição pós-moderna das identidades: "é razoável considerar o romance como o ponto de partida da exploração de Roth da etnicidade pós-moderna. É o seu primeiro trabalho a assumir plenamente o self étnico, e faz isso dentro dos limites do pós-modernismo" (ROYAL, 2002, p. 423). E aí o livro representaria um momento de passagem dessa investigação que tinha Zuckerman como personagem central nos textos anteriores e que passaria a ter o personagem Philip Roth como objeto de estudo nos quatro livros seguintes, a tetralogia "autobiográfica" de que fazem parte os já citados Deception e The Facts, bem como Operation Shylock (Operação Shylock, 1994) e Patrimony (Patrimônio, 1991), pois “tanto na ficção quanto na não ficção [existe] uma abordagem pós-moderna na interpretação da construção de textos e identidades" (ROYAL, 2002, p. 427). 
São quatro livros que têm o protagonista em comum e lidam muito diretamente com as relações entre ficção e autobiografia. Deception já foi comentado anteriormente e The Facts será discutido em breve, Patrimony, que talvez seja o mais direto dos quatro textos, narra a história da morte do pai de Roth e da convivência de ambos. Já Operation Shylock relata uma visita do personagem Philip Roth a Israel, após descobrir que outro Philip Roth estava ali, durante o julgamento de um suposto criminoso de guerra nazista, defendendo que a salvação do judaísmo estaria no que ele denominou de "diasporismo", o retorno dos judeus para a Europa e o consequente esvaziamento do Estado de Israel. O romance termina com a seguinte nota: "Este livro é uma obra de ficção [...] Os nomes de personagens, lugares e incidentes são ou produto da imaginação do autor, ou usados ficcionalmente. Qualquer semelhança com fatos, locais e pessoas reais, vivas ou mortas, é mera coincidência. Esta confissão é falsa" (ROTH, 1994, p. 357).

Afora a ironia óbvia, já que é exatamente essa aparente impossibilidade de distinguir entre o fato e a ficção, entre o romance e a autobiografia, um dos temas centrais do texto, os sentidos dessa nota final são mais complicados. O título completo do livro é Operação Shylock - Uma confissão, ou seja, quando, na derradeira linha, o narrador anuncia que "esta confissão é falsa", não há como saber a qual das confissões ele está se referindo: se a confissão do título, o que significaria que o que estamos lendo se encontra inteiramente no campo da ficção, ou se a confissão das linhas anteriores, que diz que se trata de um livro fictício, o que indicaria que, apesar de um enquadramento ficcional, os fatos ali contados são "verdadeiros" e realmente aconteceram com o autor.

Se é evidente que pelo menos três dos quatro livros lidam com uma zona de indeterminação, que em graus distintos aproxima ou afasta o real e o inventado e, ao mesmo tempo, é teoricamente aceitável considerar que eles se configuram com base na permeabilidade, na fluidez das identidades contemporâneas, parece-me que, com exceção talvez de Patrimony, um belíssimo balanço da figura paterna, o biográfico é estratégico, é o instrumento escolhido - um dos principais instrumentos utilizados pelo romance nas últimas décadas - para reafirmar o ficcional. Os três livros podem ser aproximados de modos significativos a The Counterlife, mas a relação mais direta é com The Facts, o texto que vem cronologicamente logo depois dele na produção de Roth.

O vínculo surge já na epígrafe, que reproduz uma frase de Nathan 
Zuckerman retirada de The Counterlife: "Enquanto ele falava, eu ia pensando, as histórias em que as pessoas transformam a vida, as vidas em que as pessoas transformam as histórias" (ROTH, 2016). É uma frase síntese do que leremos no livro, dividido em três partes. A parte central, que é a maior delas, ocupando quase $80 \%$ da obra, narra momentos da vida de Roth da infância até a sua consolidação como escritor, com Portnoy's Compaint, quando tinha cerca de 35 anos (o livro foi escrito com o autor com 55 anos), dedicando especial atenção a algumas de suas difíceis relações amorosas.

Se fosse apenas isso, seria uma quase autobiografia tradicional, tanto que as informações documentadas ali são usadas com bastante frequência na já citada biografia intelectual de Claudia Roth Pierpont. São as cartas que veem antes e, principalmente, depois dessa parte central que transformam a compreensão do livro. Na carta de abertura do volume, Roth escreve para o seu personagem e pede para que ele leia o manuscrito da obra. Pode-se repetir o raciocínio: se ele parasse aqui, ainda estaríamos em um patamar de certa "normalidade". O autor faz uma brincadeira com seu personagem mais famoso e aproveita essa brincadeira para avisar para seus leitores que mudou alguns nomes ou detalhes identificadores para evitar constrangimentos, que se sente inseguro de trabalhar sem o auxílio de sua imaginação, que o texto foi escrito sob o impacto da morte dos pais e o medo da própria morte, ou seja, teríamos uma espécie de prefácio espirituoso para a exposição das memórias. É a carta final que muda tudo, porque ali Zuckerman responde. Ele lê o texto e diz, já no início das trinta páginas, que o resultado é fraco e que o livro não deveria ser publicado: "Li o manuscrito duas vezes. Aqui vai a franqueza que me pediu: não publique, você faz muito melhor escrevendo sobre mim do que relatando ‘com exatidão' sua própria vida” (ROTH, 2016, p. 171).

Na continuação, Zuckerman ataca três questões distintas: a) aponta os defeitos da biografia, as omissões, as inseguranças, o tratamento incompleto e tímido das personagens femininas, as mudanças de nomes; b) reflete sobre a própria existência diante do seu criador, um pouco como o Ricardo Reis de O Ano da morte de Ricardo Reis, de Saramago, perplexo por existir e, de certa forma, superar aquele que o concebeu; c) faz uma análise das vantagens da imaginação sobre os fatos e do papel da ficção: "seu instrumento para uma autoevisceração realmente impiedosa, seu instrumento para uma genuína autoconfrontação, sou eu" (ROTH, 2016, p. 195). E então o leitor de The Counterlife é surpreendido pelo aparecimen- 
to no texto de Maria, que, naquele livro, é num determinado momento amante do irmão de Nathan e, em outro, a sua própria amante e, depois, sua mulher. Aqui, ambos são casados, o personagem conseguiu superar o antissemitismo da família da esposa (amplamente discutido no último capítulo do romance), ele mora na Inglaterra e estão esperando um filho. Aquilo que fizera parte da compulsão de inventar do personagem em The Counterlife, um dos "se/então" que ele cria porque não consegue não transfigurar a "vida", assume em The Facts o lugar de verdade dentro do universo ficcional: a instabilidade que o personagem aponta na recriação biográfica de seu criador reconstrói-se como instabilidade de sua própria biografia, que não se sustenta de um livro para o outro. Não há limites para a invenção nem qualquer certeza, consciência que essa Maria que aqui ressurge demonstra plenamente ao temer o que o autor poderá fazer com ela e o marido, já que com os dois ele nunca terá o mesmo pudor que teve consigo mesmo: "Mas eu não quero ser interessante! Quero ser deixada em paz com coisas que não tenham nenhum grande interesse. Criar um filho" (ROTH, 2016, p. 203). Ou, nas palavras de Zuckerman:

Agora ela está deitada sozinha no quarto às escuras, aterrorizada com a possibilidade de nunca sermos outra coisa senão aquilo que você, com sua biografia excessiva, determinar; que nunca teremos a boa fortuna, ou nosso filho, de viver como aqueles personagens que, segundo alguns autores inocentemente afirmam, em certo momento, "assumem o controle" e ditam sua própria narrativa. O que ela está dizendo é: "Ah, meu Deus, lá vem ele de novo - vai foder conosco" (ROTH, 2016, p. 204).

$\mathrm{Na}$ carta que abre o volume, o duplo do autor, o personagem Philip Roth, diz para o seu duplo transfigurado, o personagem Nathan Zuckerman, que "se de certo modo $O$ avesso da vida [The Counterlife] pode ser lido como uma ficção sobre a estrutura, então isso aqui são os ossos descarnados, a estrutura de uma vida sem a ficção" (ROTH, 2016, p. 12). Talvez, depois de toda essa discussão, seja possível reformular um pouco a afirmação, propondo que The Counterlife seja uma ficção sobre a estrutura da ficção e que The Facts, texto no qual o personagem inventado mostra para o seu inventor que, sem invenção, as suas criações desmoronam, que The Facts seja, no final das contas, sobre a impossibilidade de estruturar uma vida sem ficção. 


\title{
THE FICTIONAL IMPOSITION IN THE COUNTERLIFE AND THE FACTS, BY PHILIP ROTH
}

\begin{abstract}
This article aims to discuss the relation between fiction and autobiography in Philip Roth's work, by specifically tackling the books The Counterlife, the 1986 novel that is Roth's most radical experimentation in fiction, and The Facts, an "autobiographic" text published by him a short time after that, in 1988. The objective of the analysis is to show how intertwined these two works are, that the clash between life and invention is ever-present in both of them, and that invention is invariably the winning force.

KEYWORDS: Fiction. Contemporary novel. Autobiography. Philip Roth.
\end{abstract}

\section{NOTAS}

${ }^{1}$ Este texto foi produzido no âmbito de um projeto de pesquisa financiado pela Fundação de Apoio à Pesquisa do Estado de São Paulo (Fapesp), processo 2015/02207-7.

${ }^{2}$ Essa hipótese, aqui levantada para discutir a obra de Roth, já foi testada em artigos produzidos sobre romances de J. M. Coetzee (SCHWARTZ, 2015; 2017) e Ricardo Piglia (SCHWARTZ, 2013). A discussão mais teórica sobre esse "ambiente nada propício" está no artigo "A tendência autobiográfica do romance contemporâneo", publicado por mim também em 2013, ainda que a ideia de um ambiente nada propício para a fícção - e a arte de modo geral - ganhe no ano em que este texto está sendo escrito, em 2017, tons bastante mais fortes e dramáticos.

${ }^{3}$ As cartas aqui citadas foram pesquisadas na coleção Philip Roth, na Biblioteca do Congresso dos Estados Unidos, em abril de 2016. Elas foram liberadas para pesquisa em 2011 e fazem parte de um acervo imenso de mais de 25 mil itens do escritor distribuídos em 255 caixas. Neste artigo, as referências às cartas seguirão este modelo: Susan Sontag, caixa 32, material de Philip Roth, Divisão de manuscritos, Biblioteca do Congresso, Washington, D.C.

${ }^{4}$ Um primeiro rascunho do texto mostra que o título inicial do livro era You Must Change you Life (Você precisa mudar a sua vida, citado em SHOSTAK, 2004, p. 204). 
${ }^{5}$ Sigo aqui, com alterações, o formato do resumo proposto por MASIERO (2011, p. 97-98).

${ }^{6}$ Mary McCarthy, caixa 23, material de Philip Roth, Divisão de manuscritos, Biblioteca do Congresso, Washington, D.C.

${ }^{7}$ Ozick-Roth, caixa 26, material de Philip Roth, Divisão de manuscritos, Biblioteca do Congresso, Washington, D.C.

${ }^{8}$ SHOSTAK (2004, p. 205) também afirma a importância da passagem, mas não centra a sua análise nela, enxergando-a mais como uma confirmação do caráter transitório de qualquer uma das narrativas contraditórias do romance.

\section{REFERÊNCIAS}

LEE, Hermione. The Art of Fiction. In: SEARLES, George J. (Org.). Conversations with Philip Roth. Jackson: University Press of Mississippi, 1992. p. 162-187.

MASIERO, Pia. Philip Roth and the Zuckerman Books: The Making of a Storyworld. Nova York: Cambria Press, 2011.

. Roth's The Counterlife and the Negotiation of Reality and Fiction.

Comparative Literature and Culture, Pardue, v. 16, n. 2, 2014. Disponível em: $<$ http://docs.lib.purdue.edu/clcweb/vol16/iss2/13/>. Acesso em: 15 nov. 2017.

PIERPONT, Claudia Roth. Roth libertado, o escritor e seus livros. São Paulo: Companhia das Letras, 2014.

ROTH, Philip. American Pastoral. Nova York: Vintage, 1998 (tradução: Pastoral Americana. São Paulo: Companhia das Letras, 1998).

. Deception. Nova York: Hougton Mifflin Company, 1990 (tradução: Mentiras. São Paulo: Siciliano, 1991).

. Exit Ghost. Nova York: Hougton Mifflin, 2007 (tradução: Fantasma sai de cena. São Paulo: Companhia das Letras, 2008).

. I Married a Communist. Nova York: Hougton Mifflin, 1998 (tradução:

Casei com um comunista. São Paulo: Companhia das Letras, 2008).

. Operation Shylock. Nova York: Hougton Mifflin, 1993 (tradução:

Operação Shylock. São Paulo: Companhia das Letras, 1994).

. Patrimony. Nova York: Farrar, Straus and Giroux, 1991 (tradução:

Patrimônio. São Paulo: Companhia das Letras, 2012). 
The Counterlife. Nova York: Farrar, Straus and Giroux, 1987 (tradução: O avesso da vida. São Paulo: Companhia das Letras, 2008).

The Facts. Nova York: Farrar, Straus and Giroux, 1988 (tradução: Os fatos. São Paulo: Companhia das Letras, 2016).

. The Human Stain. Nova York: Vintage, 2001 (tradução: A marca humana. São Paulo: Companhia das Letras, 2002).

. The Plot against America. Nova York: Hougton Mifflin, 2004 (tradução: Complô contra a América. São Paulo: Companhia das Letras, 2005).

. Zuckerman Bound: a Trilogy \& Epilogue 1979-1985. Nova York: The Library of America, 2007 (tradução: Zuckerman acorrentado: três romances e um epílogo. São Paulo: Companhia das Letras, 2011.)

ROYAL, Derek Parker. Postmodern Jewish Identity in Philip Roth's The Counterlife. Modern Fiction Studies, v. 48, n. 2, p. 422-443, summer 2002.

SCHWARTZ, Adriano. A biografia de uma ficção: o romance dentro do romance em Respiração artificial de Ricardo Piglia. Revista USP, v. 97, p. 82-91, mar./ abr./maio 2013.

. A tendência autobiográfica do romance contemporâneo: Coetzee, Roth e Piglia. Novos Estudos Cebrap, n. 95, p. 83-97, mar. 2013.

. A vida da ficção na nova idade das trevas. In: ROSENFIELD, Kathrin H.; PEREIRA, Lawrence Flores (Org.). Lendo J. M. Coetzee. Santa Maria: UFSM, 2015. p. 147-159.

. Coetzee, leitor de Barthes. In: REIMÃO, Sandra; RIAUDEL, Michel

(Org.). Livros, literatura \& história: passagens Brasil-França. Florianópolis: Escritório do Livro, 2017. p. 151-162.

SHOSTAK, Debra. Philip Roth: Countertexts, Counterlives. Columbia: South Carolina University Press, 2004.

TUERK, Richard. Caught between The Facts and Deception. In: ROYAL, Derek Parker (Org.). Philip Roth, new Perspectives on an American Author. Londres: Praeger, 2005. p. 129-142.

Recebido em: 31/08/2017

Aceito em: 15/12/2017 